\title{
Bilateral cilio-retinal artery occlusion in classic migraine
}

\author{
P.G. Hykin, D. Gartry, D.J. Brazier and E. Graham \\ The Medical Eye Unit, St. Thomas's Hospital, Lambeth Palace Road, London SE11, UK
}

\begin{abstract}
Summary: A case of bilateral cilio-retinal artery occlusion in a patient with classic migraine is described. It is unlikely that this hitherto unreported occurrence represents altered tone in the dense adrenergic innervation to the posterior ciliary circulation. We advise the continued use of beta-adrenergic blockers as prophylaxis in ocular migraine.
\end{abstract}

\section{Introduction}

Permanent infarctions in ocular migraine usually involve the retinal circulation. ${ }^{1,2}$ Posterior ciliary circulation infarcts are less well reported ${ }^{3}$ but include one case of unilateral cilio-retinal artery occlusion. ${ }^{4}$ The posterior ciliary vessels and the central retinal artery posterior to the lamina cribrosa are adrenergically innervated. ${ }^{5}$ These factors were believed important in three cases of ocular infarction that occurred shortly after propanolol, a mainstay of migraine prophylaxis, was commenced, ${ }^{6}$ leading to a less frequent use of the drug in ocular migraine. Our patient suffered two separate ocular circulation infarcts, but was treated with propanolol with no adverse effects.

\section{Case report}

A 29 year old female suddenly noticed a small scotoma nasal to fixation in her left eye, 3 days after the start of an attack of classic migraine characterized by fortification spectra, headache and nausea. She had developed migraine 7 years earlier and had experienced one attack in the mid-cycle phase of each month ever since. She was taking an oral contraceptive pill. Right and left visual acuities were 6/4. Right and left near vision was N5 and she saw all 17 Ishihara colour plates with each eye. Pupil responses were normal, and there was no relative afferent pupillary defect. Anterior segments were normal and intraocular pressures were $12 \mathrm{mmHg}$. An absolute wedge shaped field defect was present nasal to fixation in her left eye. Fundoscopy revealed occlusion of the left cilioretinal artery (Figure 1). The right fundus was normal. Cardiac evaluation was unremarkable, no carotid bruits were heard and there was no evidence

Correspondence: P.G. Hykin, F.R.C.S., Moorfields Eye Hospital, City Road, London ECl, UK

Accepted: 20 September 1990 of a collagen vascular disease. Blood count and film, clotting factors including anti-thrombin $3>-$ level, serum fibrinogen and biochemistry weres normal. Lupus anti-coagulant was not found. The erythrocyte sedimentation rate was 5 , antibodies to ${ }^{N}$ rheumatoid factor, antinuclear factor, double- $\supset$ stranded DNA and syphilis serology were negative. $\overrightarrow{-}$ Chest X-ray, electrocardiogram and echocardio- 3 gram were unremarkable. The oral contraceptive pill was stopped.

Six months later she presented with a scotomagnn $\vec{\Theta}$ the right eye, 2 days after the onset of a further-severe attack of classical migraine. Right and kifito visual acuities were 6/4. Near and colour vision remained normal. Both anterior segments were quiet, intraocular pressures were right $16 \mathrm{mmHg}$

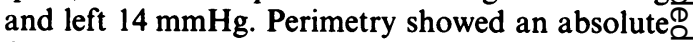
field defect infero-nasal to fixation in the right eye, $\overrightarrow{\vec{F}}$ the left field was unchanged.

Examination of the right fundus revealed retinal cloudy swelling in the distribution of the superior

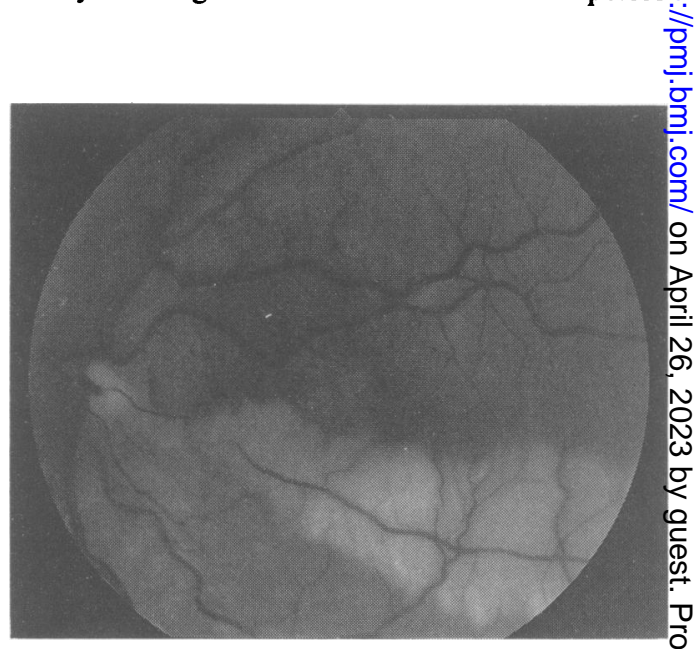

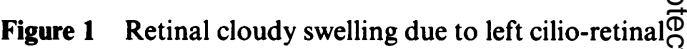
artery occlusion. 
branch of a large cilio-retinal artery (Figure 2). Fluorescein angiography showed occlusion of this vessel but dye transit time was normal in the remainder of the retinal vessels (Figure 3). Systemic examination and investigation was again unremarkable. She was commenced on propanolol $20 \mathrm{mg}$, three times a day and has had no further attacks.

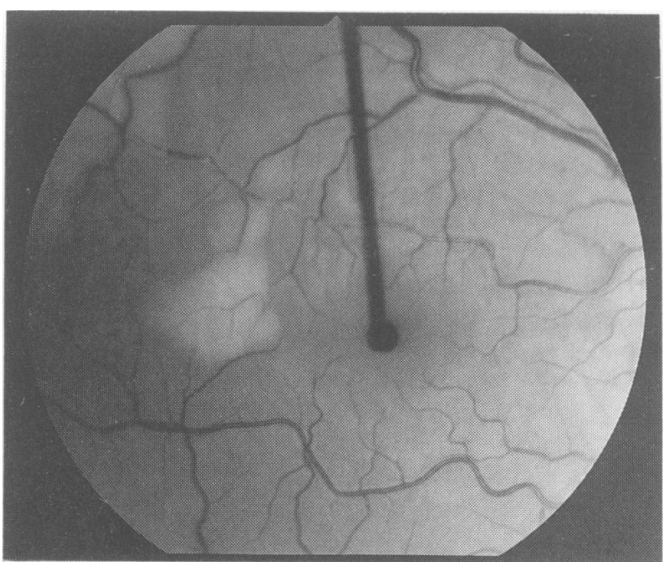

Figure 2 Retinal cloudy swelling temporal to a fixation pointer due to occlusion of the superior branch of a right cilio-retinal artery.

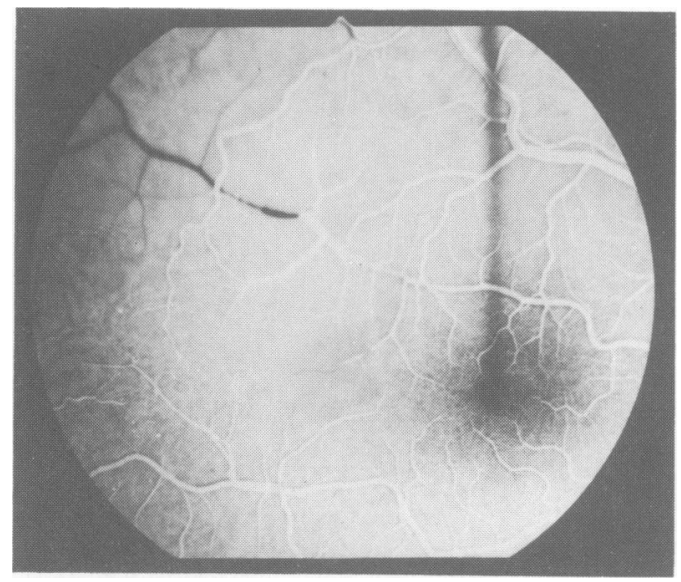

Figure 3 Mid-venous phase fluorescein angiogram, showing complete occlusion of the superior branch of the cilio-retinal artery. There is no evidence of focal arteritis.

\section{Discussion}

This patient experienced bilateral cilio-retinal artery occlusion during attacks of classical migraine. Permanent retinal infarcts are well reported in classic migraine and include central and branch retinal artery occlusion, central retinal vein occlusion, central serous retinopathy, vitreous haemorrhage, retinal haemorrhage and transient monocular visual loss. ${ }^{1-4,7}$ Posterior ciliary circulation occlusions are less frequent but include anterior ischaemic optic neuropathy, ${ }^{8}$ retinal pigment epithelial change ${ }^{9}$ and one instance of cilioretinal artery occlusion. ${ }^{4}$

The posterior ciliary circulation and the retinal circulation proximal to the lamina cribrosa are adrenergically innervated, ${ }^{5}$ and migraine-related infarction in the ocular circulation has been thought to represent reduced adrenergic vasodilator tone with resultant increased vasoconstriction. ${ }^{10}$ However, infarctions are well reported in the retinal circulation distal to the lamina cribrosa which is devoid of adrenergic innervation. Furthermore, although regional cerebral blood flow studies have shown reduced blood flow during attacks of classic migraine, evidence that this is due to autonomically mediated vasoconstriction is lacking. In fact, it is more likely that reduced cerebral blood flow is an epiphenomenon occurring secondarily to spreading cortical depression, ${ }^{11,12}$ a wave of altered cortical function and metabolic activity. Local release of vasoactive substances, such as 5-hydroxytryptamine from endothelial cells, platelet release reactions and possibly cerebral arterio-venous shunting may all be contributory factors. ${ }^{13}$

Propanolol is a well established prophylactic in classic migraine although its use in ocular migraine has been questioned recently 7,14 because it was thought to have precipitated infarction shortly after commencement of therapy, due to its effect on the adrenergic innervation to the ocular circulation. Since there is minimal evidence that this innervation is important in the pathogenesis of ocular migraine, we considered it justified to use low dose propranolol as prophylaxis in this patient, with prevention of further attacks and no adverse effects. At present therefore, we advocate the continued use of low dose propanolol in cases of ocular migraine.

\section{References}

1. Corbett, J.J. Neuroophthalmic complications of migraine and cluster headache, Neurol Clin 1983, 1: 973-995.

2. Walsh, F.B. \& Hoyt, W.F. In: Miller, N. (ed.). Clinical Neuro-ophthalmology, 9th edition, Williams and Wilkins, Baltimore, 1988, pp. 1512-1513.
3. Hupp, S.L., Kline, L.B. \& Corbett, J.J. Visual disturbances in migraine. Surv Ophthalmol 1989, 33: 221-235.

4. Lawton-Smith, J. Permanent infarctions complicating ocular migraine. J Clin Neuro-ophthalmol 1986, 6: 74-75. 
5. Wise, G.N., Dollery, C.T. \& Henkind, P. The Retinal Circulation. Harper and Row, New York, 1971.

6. Burde, R.M. Migraine. J Clin Neuro-ophthalmol 1986, 6: $72-75$.

7. Victor, D.I. \& Welch, R.B. Bilateral retinal haemorrhages and disc oedema in migraine. Am J Ophthalmol 1975, 93: 250-256.

8. MacDonald, W.I. \& Sanders, M.D. Migraine complicated by ischaemic papillopathy. Lancet 1971, ii: 521-523.

9. O'Connoor, R.C.R. Complicated migraine. A study of permanent neurological and visual defects caused by migraine. Lancet 1962, ii: 1072-1075.
10. Katz, B. Migrainous central retinal artery occlusion. J Clin Neuro-ophthalmol 1986, 6: 69-71.

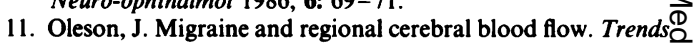
Neurosci 1985, 8: 318-321.

12. Lauritzen, M., Skyhoj, O.T. \& Lasen, N.A. Changes inregional cerebral blood flow during the course of classic migraine attacks. Ann Neurol 1983, 3: 633-641.

13. Amery, W.K., Van Nueten, J.M. \& Wauquier, A. The Pharmacological Basis of Migraine Therapy. Pitman, $\frac{\bar{G}}{\bar{D}}$ London, 1984.

14. Gray, J.A. \& Carroll, J.D. Retinal artery occlusion in $\vec{\Phi}$ migraine. Postgraduate Med J 1985, 61: 517-518. 